\title{
Interest Groups' Incentives to Cooperate in the Production of Information in the Context of the EU Policy-Making
}

\author{
Antonio García-Lorenzo ${ }^{1}$, Jesús López-Rodríguez ${ }^{2}$ and José Manuel \\ Barreiro-Viñán ${ }^{3}$
}

\begin{abstract}
:
The literature on information economics serves the European Commission to justify the participation of interest groups in response to problems of asymmetric information in the European Union (EU) policy-making processes.

Using the framework of the agency theory, the role of interest groups as information producers is incorporated into a model where the types of conditions in which they would have the incentive to cooperate in the production of information are examined.

The results of the model show that the interest group's expected utility when acting independently is equal to the reserve utility, while it increases when acting cooperatively. It can therefore be concluded that incentives for cooperation in the production of information among interest groups exist.
\end{abstract}

One potential policy implication for the EU is that the EC could decrease the conditions of the contracts, thereby diminishing the costs of obtaining information.

Keywords: Interest Groups, EU Policy-Making, Cooperation, Asymmetric Information.

JEL Classification: D72.

\footnotetext{
${ }^{1}$ Jean Monnet Group on Competition and Regional Development in the European Union, University of A Coruña.

${ }^{2}$ Jean Monnet Group on Competition and Regional Development in the European Union, University of A Coruña, e-mail: jesus.lopez.rodriguez@udc.es, jelopez@udc.es

${ }^{3}$ Jean Monnet Group on Competition and Regional Development in the European Union, University of A Coruña.
} 


\section{Introduction}

Interest groups lobby the European institutions to achieve policy decisions that are in line with their own preferences. While some argue that different interest groups are equally able to shape EU policy-making, others argue that lobbying success is systematically biased towards some powerful interest groups. In any case, the transmission of information from informed interest groups to uninformed policy makers is extremely important in determining policy outcomes.

The process of policy-making offers several possibilities for the European Commission (EC) and the interest groups to exchange information. The EC contacts the interest representatives to invite them for a discussion of the policy-making where an expertise from the interest group is required. This means that the EC needs to cooperate with interest groups on its policy-making processes. This paper studies the possibility that the EC promotes a contract as an incentive for interest groups to behave as information producers for it to obtain information and to ensure that its proposals are considered in the decision-making process. The EC requires information about the policy positions of major stakeholders to gain an informational advantage over the Council and the European Parliament and to thereby ensure their approval.

The contract is formalised by means of an agency relationship, since the EC possesses imperfect information with respect to the actions of interest groups, which must be considered in its design. The non-observable nature of interest groups' efforts in their role as information producers calls for a control system with appropriate incentives. In this context, conditions under which interest groups, in their role as information producers, find it profitable to collaborate with the EC are established. Simultaneously, incentives emerging from the optimal design of the contracts are analysed. Conditions under which the interest groups would find it profitable to act cooperatively rather than independently are focused on.

The remainder of the study is as follows: section 2 contains a brief description of available literature analysing the influence of interest groups on policy-maker's actions when these behave as information producers. Section 3 presents a principalagent model studying the incentives for cooperation given to interest groups when acting as information producers for the EC. Section 4 presents the main conclusions and future extensions.

\section{Interest Groups as Information Producers}

The participation of interest groups in policy-making is unavoidable. Literature studying the role and behaviour of interest groups in the political sphere has increased considerably over the past two decades and include a wide variety of models, from rent-seeking or information transmission lobbying to analysing the possible effects of different institutional settings or voting rules. For a more 
comprehensive analysis, see Austen-Smith (1997), Van Winden (1999), Grossman and Helpman (2001) and Reuben (2002).

Information supply is an important instrument through which interest groups can exert influence on political decisions. Information asymmetries are introduced when the assumption taken is that those interest groups are perfectly informed or at the least, more informed than the policymaker. Successful information transmission will depend on the position of the interest group's ideal policy outcome relative to the policymaker's. Crawford and Sobel (1982) analyse a model in the case of the existence of only one interest group informing the policymaker. There are several extensions to Crawford and Sobel's analysis (see for example, Farrell and Rabin (1996), Krishna and Morgan (2001), Banerjee and Somanathan (2001) and Battaglini (2002).

It would be unrealistic to assume that in politics, transmitting information to policymakers is free of cost. For this reason, models in which there is a cost to communication have been developed, for example, Potters and Van Winden (1992), Austen-Smith (1995) and Lohmann (1993; 1995).

Most literature concentrates on information transmission between the interest group and the policymaker and neglects to examine the information flow among and within the interest groups. Differing network structures among groups, group size, and the different communications channels used may have important consequences on the behaviour of the group and on how individuals perceive that behaviour (see Grossman and Helpman (2001).

In the EU interest intermediation, policy information is usually held to be the critical resource that is exchanged among policy-makers and interest groups. The central aim of interest groups is political influence. Interest groups lobby decision-makers to achieve policy decisions that are in line with their own preferences. Lobbying plays a particularly important role in the European Union (Lehmann and Bosche, 2003; Charrad, 2005; Greenwood, 2007; Coen, 2007; Schwartzkopff, 2009; Klüver, 2011; Thalassinos and Dafnos, 2015). In addition, the European Commission has engaged in participatory engineering to use interest groups inclusion to improve the democratic legitimacy of the European Union (Kohler-Koch and Finke, 2007; Bouwen, 2009; Quittkat, 2011; Klüver, 2009; 2012; Liapis et al., 2013).

\section{The Model}

It could be said that transaction costs are somehow used by the EC to justify the participation of interest groups in the decision-making process, but it should be stressed that the produced information is imperfect. Therefore, we should ask ourselves whether the interest groups which enjoy important advantages when acquiring information, should receive certain incentives from the EC. These incentives would be regulated with contracts and would allow for a more intense 
integration of interest groups into the decision-making process, acting as information producers.

We develop a theoretical model that identifies information supply and the major determinants of interest groups influence. It would be of advantage to interest groups to participate in policy making since they could augment their credibility by transmitting all the information at their disposal whilst simultaneously advancing documented opinions or preferences.

Let's assume that the preferences of the information-producing group may be expressed in the form of a utility function given by:

$$
V(w, e)=U(w)-e K
$$

Where $(w)$ represents the payment that the group receives for its collaboration with the EC. The payment that the interest group receives for acquiring and processing the information might be defined in terms of the esteem in which the EC holds the interest group. Thus, attaining and maintaining a healthy reputation should represent a natural incentive for the said group, and will condition the extent to which the group participates in the future. $(K)$ is a positive real scalar and $U($.$) is twice$ continuously differentiable and bounded, by $U^{\prime}(\cdot)>0$ and $U^{\prime \prime}(\cdot)<0$. In the same way the inverse utility function may be written as:

$$
\psi(\cdot) \equiv U^{-1}(\cdot)
$$

It is assumed that each interest group must exert an effort $(e)$, which may have a value between 0 and 1 . In short:

$(e=1)$ : Maximum effort, implying the correct evaluation of the problem.

$(e<1)$ : Indicating that the effort is below maximum, thus leading to an inexact evaluation of the problem.

Furthermore, it is supposed that due to the non-observable nature of the effort made by the interest group by the EC, the EC is unable to include this effort in the contract offered to the group. The utility of introducing the result into the contract is derived from the information it provides concerning the effort exerted by the group. This constitutes its only value given that the EC is considered neutral with respect to the risk, whilst the interest group is averse to it.

It will be in the EC's interest for the contract to include any mechanism which might provide information regarding the behavior of the interest group taking part. The result of the effort can be reflected by means of a noisy indicator $(\beta)$. It is possible for this indicator to have a value of 0 or 1 and it is affected by a source of noise, when a maximum effort achieves the correct evaluation of a problem and therefore, results in reliable information. This does not mean that the estimator must equal exactly 1 
for it to act deterministically, but rather that its value must approach 1 with a certain probability according to the effort made.

The extent to which the Council of Ministers' proposals are found to be acceptable, may be used as an indicator of the effort which the interest group exerts, on evaluating the problems that arise within the framework of the contractual relationship with the EC. Thus if $(\beta=1)$, then the proposal has been accepted and this reveals the correct evaluation of the problem. Conversely, if $(\beta=0)$, the proposal is then rejected which means that the evaluation of the problem was inexact. Furthermore, the indicator is sometimes affected by a source of noise because of the lack of political motivation or simple inertia affecting those governments that make up the Council and this factor sinks the EC's proposals.

In accordance with the given outline, the general proposal for the procedure would be as follows: Firstly, the EC would decide on the contract to offer the interest group. The interest group would then accept or reject the contract depending on its terms. To understand the nature of the difficulties faced by the EC prior to designing the contract, it should be noted that in the event of the conditions for obtaining information and the effort required to obtain it are asymmetric it is possible for the EC to propose the amount of effort it would wish the group to exert. However, it is not possible to reflect this effort in the terms of the contract. Therefore, the EC must take into consideration that the interest group can choose the level of effort once the contract has been signed, which is most advantageous from their point of view given the nature of the contract. In short, the EC may propose a certain level of effort, but this should correspond to the level that the interest group is willing to exert. A model enabling the comparison of two alternative scenarios for the interest groups has been set up. These differ in that they either act independently in the production of information or cooperate to acquire it.

\section{a) Solution of the model when interest groups act independently ${ }^{4}$}

Consequently, the probabilities associated with the indicator and which are conditioned by the effort carried out by the interest group, can be defined in the following way:

$$
\begin{gathered}
p[\beta=1 \mid e<1]=q \\
p[\beta=1 \mid e=1]=r \\
p[\beta=0 \mid e<1]=1-q \\
p[\beta=0 \mid e=1]=1-r
\end{gathered}
$$

\footnotetext{
${ }^{4}$ We extend the framework of Garcia-Lorenzo (2003) by solving the model when interest groups act cooperatively.
} 
If the probability of the indicator being correct is greater than the probability of it being incorrect, then the following expression must hold true:

$$
1>r>q>0
$$

Given that the effort made by the interest group benefits the EC, it is highly likely that a contract encouraging maximum effort will be offered $(e=1)$, achieving two goals; on the one hand it allows the EC to ensure that the information used in the elaboration of policy is reliable and thus helps to prevent the proposals from being discredited at the Council of Ministers, and on the other, it clears up any possible remaining doubts with respect to the credibility of the information-producing interest groups. The contract may therefore be expressed in the following way:

$$
\begin{aligned}
& \Lambda(\beta)=W^{H}, \text { if } \beta=1 \\
& \Lambda(\beta)=W^{L} \text {, if } \beta=0
\end{aligned}
$$

Where $\left(W^{H}\right)$ and $\left(W^{L}\right)$ represent the payments made by the EC to the interest group. As previously stated, the EC will use the result as a source of information regarding the behaviour of the interest group. Consequently, the payment will depend upon the information produced whereby this payment will increase in accordance with the result, which in turn will result in the tendency for the interest group to increase the exerted effort. Finally, the letter $(\mathrm{H})$ is used to indicate a high level of effort and the letter (L) to indicate low effort.

Formally, the expression for the expected utility of the interest group as a function of effort may be written as follows:

$$
\begin{array}{r}
E U(e=1)=r w^{H}+(1-r) w^{L}-K \\
E U(e<1)=q w^{H}+(1-q) w^{L}-e K
\end{array}
$$

Where $U\left(W^{H}\right)=w^{H}$ and $U\left(W^{L}\right)=w^{L}$.

In order to calculate the optimum contract ${ }^{5}$, a solution to the following programme must be found by the EC:

$$
\operatorname{Min}_{\left[w^{H}, w^{L}\right]} r \psi\left(w^{H}\right)+(1-r) \psi\left(w^{L}\right)
$$

subject to (5) and (6).

\footnotetext{
${ }^{5}$ The case when the EC is neutral with respect to the risk and the interest group is averse to it will be studied.
} 


$$
\begin{gathered}
r w^{H}+(1-r) w^{L}-K \geq \underline{V} \\
(r-q)\left(w^{H}-w^{L}\right) \geq K(1-e) \quad \forall e \in[0,1]
\end{gathered}
$$

Where (5) ensures that an individually rational (IR) group accepts the contract ( $E U(e=1)>\underline{V}$ ) and equation (6) ensures incentive compatibility (IC) in order to motivate the group to select $(e=1)$. This equation reflects the fact that the interest group is willing to choose the option that the EC proposes $(e=1)$ if that option maximizes its objective function, which is $\operatorname{EU}(e=1) \geq E U(e<1)$. Since the (IC) constraint will be most binding for $(e=0)$, it can be rewritten as: $(r-q)\left(w^{H}-w^{L}\right) \geq K$.

After solving for first-order optimality conditions, the following results are reached:

$$
\begin{aligned}
& \bar{w}^{L}=\underline{V}-K \frac{q}{r-q} \\
& \bar{w}^{H}=\underline{V}+K \frac{1-q}{r-q}
\end{aligned}
$$

The solution to the programme resolved by the EC to design the optimum contract may be defined in the following way:

$$
\begin{aligned}
& \bar{W}^{H}=\psi\left[\underline{V}+K \frac{l-q}{r-q}\right] \\
& \bar{W}^{L}=\psi\left[\underline{V}-K \frac{q}{r-q}\right]
\end{aligned}
$$

Where $\left(\bar{W}^{H}\right)$ and $\left(\bar{W}^{L}\right)$ represent the optimum values for the payments made by the EC to the interest group.

The interest group's expected utility, considering the payments made by the EC and equation (1), will be as follows:

$$
E U(e=1)=r \bar{w}^{H}+(1-r) \bar{w}^{L}-K
$$

The following is obtained when substituting $\bar{w}^{H}$ and $\bar{w}^{L}$ for its optimal values:

$\left.E U(e=1)=r \underline{V}+r K \frac{1-q}{r-q}-r \underline{V}+r K \frac{q}{r-q}\right)+\underline{V}-K \frac{q}{r-q}-K=r K \frac{1}{r-q}-r K \frac{q}{r-q}+r K \frac{q}{r-q}-K \frac{q}{r-q}+\underline{V}-K=\underline{V}+K \frac{r-q}{r-q}-K=\underline{V}$

From this result, the following conclusion may be drawn: The interest group's expected utility, considering the payments made by the $\mathrm{EC}$ and equation (1), is equal to the reserve utility: $V(w, e)=\underline{V}$ 


\section{b) Solution of the model when interest groups act cooperatively}

In this scenario it is presumed that each interest group produces information and that the contract offered to them by the EC has identical characteristics. Furthermore, it is assumed that the payments will be shared in equal proportions if cooperation is more profitable than acting independently. Considering the participation of two interest groups $\left(g_{1}\right.$ and $\left.g_{2}\right)$, the probabilities associated with the indicator which are conditioned by the effort carried out by the interest groups can be defined in the following way:

$$
\begin{gathered}
p\left[\beta_{g 1}=1, \beta_{g 2}=1 \mid e=1\right]=r^{2} \\
p\left[\beta_{g 1}=1, \beta_{g 2}=0 ; \beta_{g 1}=0, \beta_{g 2}=1 \mid e=1\right]=2 r(1-r) \\
p\left[\beta_{g 1}=0, \beta_{g 2}=0 \mid e=1\right]=(1-r)^{2}
\end{gathered}
$$

As previously mentioned, the EC induces each group to exert the maximum effort $(e=1)$. Therefore, the contract may be expressed as follows:

$$
\begin{gathered}
\Lambda(\beta)=W^{H} \text {, if } \beta_{g 1}=1, \beta_{g 2}=1 \\
\Lambda(\beta)=W^{L} \text {, if } \beta_{g 1}=0, \beta_{g 2}=0 \\
\Lambda(\beta)=W^{L H}=\frac{W^{H}+W^{L}}{2} \text {, if } \beta_{g 1}=1, \beta_{g 2}=0 ; \beta_{g 1}=0, \beta_{g 2}=1
\end{gathered}
$$

Where $\left(W^{H}\right)$ and $\left(W^{L}\right)$ represent the payments made by the EC to the interest groups.

Considering that the interest groups are risk averse, they will accept a lower payment in the absence of uncertainty regarding the estimation of their effort by the EC. Consequently, the EC will hold higher payments when there is uncertainty in the estimation of the effort made by the interest group in comparison with a situation in which the uncertainty vanishes. Therefore, in mathematical terms the result is the following:

$$
w^{L H}>\bar{w} \quad \text { where } \quad \bar{w}=\frac{\bar{w}^{H}+\bar{w}^{L}}{2}
$$

This result can be easily obtained applying Jensen's inequality. Taking the above equations into account, the expected utility for each interest group of the payments made by the EC can be expressed in the following way:

$$
E U(e=1)=r^{2}\left(\bar{w}^{H}\right)+2 r(1-r) w^{L H}+(1-r)^{2} \bar{w}^{L}-K
$$


And after substitute $\bar{w}^{H}$ and $\bar{w}^{L}$ for their values obtained in the first order optimality conditions:

$$
\begin{aligned}
& E U(e=1)=r^{2}\left(\underline{V}+K \frac{1-q}{r-q}\right)+2 r(1-r) w^{L H}+(1-r)^{2}\left(\underline{V}-K \frac{q}{r-q}\right)-K \\
& E U(e=1)=r^{2}\left(\underline{V}+K \frac{1-q}{r-q}\right)+2 r(1-r)\left(w^{L H}+\bar{w}-\bar{w}\right)+(1-r)^{2}\left(\underline{V}-K \frac{q}{r-q}\right)-K
\end{aligned}
$$

When considering that $\bar{w}=\frac{\bar{w}^{H}+\bar{w}^{L}}{2}$ the expression below is obtained:

$$
E U(e=1)=r^{2}\left(\underline{V}+K \frac{1-q}{r-q}\right)+2 r(1-r)\left(w^{L H}-\bar{w}\right)+2 r(1-r) \frac{1}{2}\left\{\left(\underline{V}+K \frac{1-q}{r-q}\right)+\left(\underline{V}-K \frac{q}{r-q}\right)\right\}+(1-r)^{2}\left(\underline{V}-K \frac{q}{r-q}\right)-K
$$

The expression obtained for the expected utility for each interest group of the EC's payments is the following:

$$
\begin{aligned}
& E U(e=1)=V+K+2\left(w^{L H}-\bar{w}\right) r(1-r)-K \\
& V(w, e)=\underline{V}+2\left(w^{L H}-\bar{w}\right) r(1-r)
\end{aligned}
$$

Considering that $w^{L H}>\bar{w}$, the expected utility of each interest group is higher in the case that they act cooperatively than when they do not.

\section{Conclusions and future extensions}

This paper provides important insights for the study of the type of contracts the EC offers to the interest groups. The interest groups are assigned the role of information producers and are deemed able to solve inefficiencies stemming from the existence of incomplete information in the decision-making process. EC contracting with the interest groups the provision of this information ensures to them their good reputation and can also be a positive sign in their political market identification. Therefore, these types of relationships are beneficial for both the EC and the interest groups and consequently, tend to last for a long period of time. This constitutes an important finding since scholars have largely attempted to explain the influence of groups based on their characteristics and, as a result, have often arrived at contradictory findings.

Within this context, using the framework of the agency theory, the role of interest groups as information producers is incorporated into a model and the types of conditions in which they would have the incentive to cooperate in the production of 
information are examined. This framework could be applied to research on interest groups in any political context as policy issues trigger the attention of interest groups no matter in which political system they are introduced. Thus, to understand the emergence of policy outcomes, one cannot solely look at the political preferences of institutions, instead we must examine how their preferences come about.

The results of the model show that the interest group's expected utility when acting independently is equal to the reserve utility, while it increases when acting cooperatively. It can therefore be concluded that incentives for cooperation in the production of information among interest groups exist. Finally, given that the expected utility of interest groups increases cooperating, the EC could decrease the conditions of the contract, thereby diminishing the costs of obtaining information. Consequently, this article contributes to our knowledge of preference formation within the EC.

It is commonly assumed that interest groups are experts acquiring information. However, if it is a matter of expertise, it is not plausible that there are insufficient qualified experts for the government to select one with whom it shares similar preferences over policy. In summary, a more satisfactory explanation of the way information is acquired by interest groups should be put forward. In any case, our results show that interest groups are actively seeking to influence policy formulation and that they are indeed able to shape the EC proposals if they can provide information. Future research therefore needs to systematically consider interest groups pressure when trying to explain policy outcomes in the European Union. In the proposed model, the assumption of perfect internal monitoring eliminates the risk of the benefits of cooperation disappearing due to a moral hazard problem. This limitation allows for the possibility of new theoretical developments and the extension of the model, introducing either an interested or uninterested monitoring mechanism. Therefore, a fruitful research avenue would be to characterise the equilibrium under conditions of costly internal monitoring.

\section{References:}

Austen-Smith, D. 1995. Campaign contributions and access. American Political Science Review, 89, 566-581.

Austen-Smith, D. 1997. Interest groups: Money, information and influence. In D.C. Mueller (Ed.), Perspectives on Public Choice. Cambridge: Cambridge University Press.

Banerjee, A. and Somanathan, R. 2001. A simple model of voice. Quarterly Journal of Economics, 116, 189-228.

Battaglini, M. 2002. Multiple Referrals and Multidimensional Cheap Talk. Econometrica, 70, 1379-1401.

Bouwen, P. 2009. The European Commission, in David Coen and Jeremy Richardson (ed.), Lobbying in the European Union: Institutions, Actors and Issues. Oxford University Press, 19-38.

Charrad, K. 2005. Lobbying in the European Union, Junior Research Group European 
Civil society and multilevel governance. Münster, Westfälische WilhelmsUniversität Münster.

Coen, D. 2007. Lobbying in the European Union, European Parliament's Committee on Constitutional Affairs. Brussels, European Parliament.

Crawford, V.P. and Sobel, J. 1982. Strategic Information Transmission. Econometrica, 50, 1431-1451.

Farrell, J. and Rabin, M. 1996. Cheap talk. Journal of Economic Perspectives, 10, 103-118.

Greenwood, J. 2007. Interest Representation in the European Union, $2^{\text {nd }}$ ed. Basingstoke, Palgrave MacMillan.

Grossman, G.M. and Helpman, E. 2001. Special interest politics, Cambridge, The MIT Press.

Klüver, H. 2009. Measuring Interest Group Influence using Quantitative Test Analysis, European Union Politics, 10(4), 535-549.

Klüver, H. 2011. The Contextual Nature of Lobbying: Explaining Lobbying Success in the European Union. European Union Politics, 12(4), 483-506.

Klüver, H. 2012. Biasing Politics? Interest Group Participation in EU Policy-Making. West European Politics, 35(5), 1114-1133.

Kohler-Koch, B. and Finke, B. 2007. The Institutional Shaping of EU-Society Relations: A Contribution to Democracy via Participation? Journal of Civil Society, 3(3), 205221.

Krishna, V. and Morgan, J. 2001. A model of expertise. Quarterly Journal of Economics, $116,747-775$.

Lehmann, W. and Bosche, L. 2003. Lobbying in the European Union: current rules and practices, Constitutional Affairs Series, AFCO 104 EN. International and Constitutional Affairs Division. Luxembourg, European Parliament.

Liapis, K., Rovolis, A., Galanos, C. and Thalassinos, I.E. 2013. The Clusters of Economic Similarities between EU Countries: A View Under Recent Financial and Debt Crisis. European Research Studies Journal, 16(1), 41-66.

Lohman, S. 1993. A signalling model of informative and manipulative political action. American Political Science Review, 87, 319-333.

Lohmann, S. 1995. A signalling model of competitive political pressures. Economics and Politics, 7, 181-206.

Potters, J. and Van Winden, F. 1992. Lobbying and asymmetric information. Public Choice,74, 269-292.

Quittkat, C. 2011. The European Commission's Online Consultations: A Success Story? Journal of Common Market Studies, 49(3), 653-674.

Reuben, E. 2002. Interest Groups and politics: The need to Concentrate on Group Formation. Mimeo, CREED and Tinbergen Institute, Department of Economics, University of Amsterdam.

Schwartzkopff, J. 2009. Splendid Isolation? The Influence of Interest Groups on EU Trade Policy, Berlin Working Paper on European Integration $N^{\circ}$. 12. Berlin, Otto Suhr Institute of Political Science of the Frei Universität Berlin.

Thalassinos, I.E. and Dafnos, G. 2015. EMU and the process of European integration: Southern Europe's economic challenges and the need for revisiting EMU's institutional framework. Chapter book in Societies in Transition: Economic, Political and Security Transformations in Contemporary Europe, 15-37, Springer International Publishing, DOI: 10.1007/978-3-319-13814-5_2.

Van Winden, F. 1999. On the economic theory of interest groups: Towards a group frame of reference in political economics. Public Choice, 100, 1-29. 